\title{
Vision Without the Eye: Following the Material of Abstract Photography
}

\section{Jelena Stojković}

'Because we believe it, we think we are seeing it.'

Vilém Flusser

\subsection{Premise // Vision}

Digital vision, Sean Cubitt writes, begins with a withdrawal of the eye. ${ }^{1}$ The machine, on which we are ever so increasingly relying for visualising the world, self-evidently, does not and cannot see in the same manner as the eye, and this factual situation determines the status of our now predominant vision. The machine continues to collect, compare and assemble visual data, but the articulating role that the eye performed in the past is now taken over by

${ }^{1}$ Sean Cubitt, The Practice of Light: A Genealogy of Visual Technologies from Prints to Pixels (Cambridge, Massachusetts: The MIT Press, 2014), 108. 
entirely automated systems of measurement and statistical comparison. ${ }^{2}$ Not only that, but increasingly, our every interaction with the machine feeds precisely that system. As Hito Steyerl warns us, we are becoming accustomed to not seeing anything intelligible, as the processes of filtering, decrypting and pattern recognition replace vision itself. ${ }^{3}$

This is, of course, nothing new. As Gilles Deleuze famously pointed out, the machine evolves together with us; its mutation is our mutation. ${ }^{4}$ That we cannot write it out from the manner in which we see is already accepted in the concept of machinic vision, which John Johnston (following Deleuze and his work with Félix Guattari) defined as not only implying a type of seeing that is enabled by the machine but also in relation to it. ${ }^{5}$ The complicity of the camera in the historical development of this vision does not need to be reasserted: the apparatus, described as the most extraordinary invention in vision in possibly the whole of human history, was supposed to deliver the promise of technology's ability to enrich and improve human sight. ${ }^{6}$ The 'mechanical retina', a term associated with the camera in the nineteenth century, rendered visible what was invisible to the eye - the surface of

2 Ibid.

${ }^{3}$ Hito Steyerl, 'A Sea of Data: Apophenia and Pattern (Mis-) Recognition', E-flux Journal 72, (April, 2016) http://www.e-flux. com/journal/72/60480/a-sea-of-data-apophenia-and-pattern-misrecognition/ (accessed 22 January 2017)

${ }^{4}$ Gilles Deleuze, 'Postscript on the Societies of Control', October 59 (1992): 6 .

5 John Johnston, 'Machinic Vision', Critical Inquiry 26 (1999): 29.

${ }^{6}$ Martin Jay, Downcast Eyes: The Denigration of Vision in TwentiethCentury French Thought (Berkeley: University of California Press, 1993), 124. 
the Moon, or the movements of a trotting horse's hooves, for instance - but it also became entangled with the systems for measuring, classifying and the ordering of the world through images. The medium's capacity to offer photographic evidence placed it in the centre of the techniques of representation and regulation that are central to the network of such modern and disciplinary institutions as the police, the prison, the press, the asylum, the family, the hospital, the school or the courtroom. ${ }^{7}$

\subsection{Argument // Material}

In 'Some Propositions on Photography' (1965), American photographer, experimental filmmaker and writer, Hollis Frampton, describes photography as a term that brackets a number of activities: an industry, a craft, a technology, a tool, a science, a racket, a hobby, and a national pastime. ${ }^{8}$ Last of all, there is an art of photography, an activity that not only consumes the least material and funds, but is also the least noticeable. The main paradox with the art of photography is that regardless of the comparatively small territory that it occupies with regard to the other photographic 'activities', it carries a responsibility for the entirety of this field, or, in Frampton's words, 'its merits and defects, its entire possible manifestations. ${ }^{9}$ Differently said, photography's vast resonance for not only culture

${ }^{7}$ John Tagg, The Burden of Representation: Essays on Photographies and Histories (Amherst: University of Massachusetts Press, 1988), 5.

${ }^{8}$ Hollis Frampton and Bruce Jenkins, On the Camera Arts and Consecutive Matters: The Writings of Hollis Frampton (Cambridge, Massachusetts: The MIT Press, 2009), 5-6

9 Ibid., 6. 
but also science and trade, as well as its encompassing of such a diverse range of genres as fashion photography, portraiture, or snapshot, are intrinsic to photography as a fine art practice. Photography is the starting point for, and the necessary restraint of, the art of photography, as the ties between them are too entwined to sever.

It is that practice of photography (as fine art) that will be discussed here in terms of the machinic conditions of digital vision. The digital 'turn', just in case the reader might need to be reminded, has brought about a significant discussion since the 1990s about photography's ontology, or what it might be and do within changed technological parameters. Despite the initial concerns that photography as we know it might become obsolete, the prevailing verdict at the moment seems to be that the 'turn' enabled another transformation and proliferation of the medium, which assumed a central role in the computerised networks of image production and dissemination. ${ }^{10}$ The fact that this optimism might be at odds with the warnings against the disorienting nature of digital vision brings us back to Frampton's now fifty years old diagnosis: if we were to look for any radical envisioning of photography's ability to make or unmake sense of vision as we now encounter it, it is the often marginalised fine art practice that should offer us clues.

Two photographic series, Taisuke Koyama's Light Field (2015) and Nihal Yesil's Leaping Field (2015), will thus

${ }_{10}$ Alexandra Moschovi, Carol McKay, and Arabella Plouviez, eds., The Versatile Image: Photography, Digital Technologies and the Internet (Leuven: Leuven University Press, 2013); Daniel Rubenstein, Jonny Golding, and Andy Fisher, eds., On the Verge of Photography: Imaging Beyond Representation (Birmingham: ARTicle, 2013). 
provide a focus in what follows, regarding their histori$\mathrm{cal}$ and theoretical contexts as photographic abstractions. However, in addition to looking closely at what we see in those photographs we will also problematise their material basis, as in a recently posed question: what does it mean to 'follow' (and 'act' with) the material? ${ }^{11}$ Such a 'following' of the material, clearly, draws from a well-known and often quoted passage from A Thousand Plateaus: Capitalism and Schizophrenia (1980), where Deleuze and Guattari assert that matter is always in movement and flux, and that such a 'matter-flow' can only be followed. ${ }^{12}$ Jussi Parikka takes up a similar route in his recent study of the 'geology of media' and points at the fact that, seen from this perspective, the historical account of photography can be read as a story of chemicals rather than simply of inventors, experimenters, or, we might add, artists. ${ }^{13}$ Within the focus on photography as fine art the task of 'following' the material will here be taken somewhat differently, claiming that photography is not only made of materials but that it also makes with materials, as any other fine art practice does. To act out this claim and point in the direction of a possible way out of digital vision's normativity, we will engage with photographic history and criticism alongside not only media studies

${ }^{11}$ Petra Lange-Berndt, ed., introduction to Materiality (London: Whitechapel Gallery and Cambridge, Massachusetts: The MIT Press, 2015), 13.

12 Gilles Deleuze and Félix Guattari, A Thousand Plateaus: Capitalism and Schizophrenia (Minneapolis: University of Minnesota Press, 1987), 409.

13 Jussi Parikka, A Geology of Media (Minneapolis: University of Minnesota Press, 2015), 55. 
but also the area that is still termed new materialism, and especially the writing of Karen Barad.

\subsection{Surface // Light}

In Light Field, Koyama places crumpled sheets of transparent cellophane on a flatbed scanner and then employs a handheld scanner to document the process of its working, simultaneously redirecting and recording digital light as it passes through the transparent material (Figure 1). The transparency of cellophane is read in negative in this process, whereas the movement of Koyama's hand displaces the linear motion of the flatbed scanner's LED lamp into what we see as a zigzagging line intersected by a rainbow of primary colours. The creases of cellophane are rendered into a nondescript mesh, unevenly distributed across the image, while an additional line registers as a coupling, shadow companion to the main, reflecting the body of the handheld scanner. ${ }^{14}$

Light conditions all vision, and as its title indicates, Koyama's series is made both about and from light. But what is digital light, and how is its status manifested in Koyama's work? We know since Isaac Newton's experiments with optics in the seventeenth century that a ray of light is made of colours, that diffuse once they encounter a transparent obstacle - a piece of cellophane for instance - as we can observe in Koyama's series. Early physics believed

14 I am grateful to Taisuke Koyama for explaining the details of this series in our e-mail correspondence in April 2016. Light Field is published together with Photons by Taisuke Koyama Projects in 2015. 


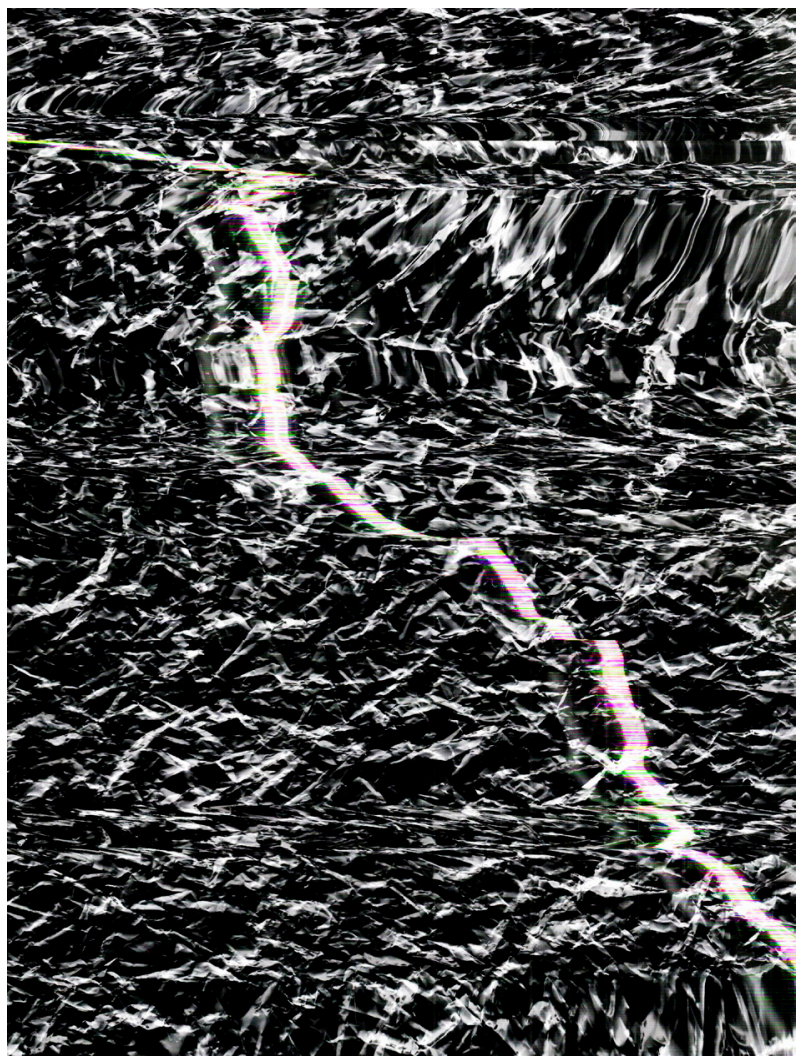

Figure 1: Taisuke Koyama, Light Field 012, 2015.

that light behaves like a stream of solid particles which becomes noticeable in its reflection on a mirror or glass surface. ${ }^{15}$ The fact that light would not be blocked by a

${ }^{15}$ Günter Leising, 'Light and Order', in Light Art from Artificial Light: Light as a Medium in $20^{\text {th }}$ and $21^{\text {st }}$ Century Art, ed. Peter Weibel (Ostfildern: Hatje Cantz, 2006), 57. 
transparent object was one of the reasons for early doubts in this theory and the basis for Thomas Young's nineteenth century 'double slit experiment', which proved that light also behaves as a wave. ${ }^{16}$ In order to approach the question of digital light, we first need to establish a difference between the understanding of light as a prime carrier of information about the world in a broad sense as that which we see and the means by which we see and the optic fibres that carry digital information in the modern world through an electrical process based on the switching between two states (one for on, and zero for off). ${ }^{17}$ Digital light, understood in this way, essentially stands for the 'digital control of the emission of light.' ${ }^{18}$ The word that needs to be stressed here is 'control', as it is the control of light, and not light itself, that is the actual foundation of contemporary, digital vision. ${ }^{19}$

In this sense, Koyama's series can be understood as the documentation of the working of digital light, or the flatbed scanner's LED lamp. However, more than simply photography, Koyama's series evokes the process of painting or drawing: it is his operation of the handheld scanner that determines the texture, density and distribution of the LED lamp's light that we see in the image. His work also involves an element of sculpting: the sheets of cellophane are placed between the two scanners in order to construct

16 Stephen Jones, 'What is Digital Light?', in Digital Light, eds. Sean Cubitt, Daniel Palmer, and Nathaniel Tkacz (London: Open Humanities Press, 2015), 84.

17 Ibid., 83-87.

18 Ibid., 90.

19 Sean Cubitt, Daniel Palmer, and Nathaniel Tkacz, eds., introduction to Digital Light (London: Open Humanities Press, 2015), 9. 
a multi-layered object for the self-induced and self-contained diffusion, distribution and recording of digital light. In both instances, it is the hand and not the eye that takes the lead in the production of the image; the photographer simply operates the machine in search of the ultimately contingent visual inscription. Before coming back to the figure of the operator, Koyama's series is important to us here for two other, intertwined elements. Firstly, what we see does not fall under the aesthetic category of representation but that of abstraction: we are not presented with anything recognisable but a pattern generated through the play of light and cellophane. However (and secondly), it is precisely this pattern (or the entanglement of light with cellophane) that we see, and it is far from being nothing.

\subsection{Cellophane // Abstraction}

Judith Brown insists that the contemporary eye has lost a capability to empathise with the excitement associated with cellophane in the past, or to read the dated 'semiotics' of the material. ${ }^{20}$ 'La Cellophane' (combining the first syllable of cellulose with the final syllable of diaphane, for 'transparent'), the company that Jacques Brandenberg set up in Switzerland in the 1910s after isolating transparent sheets of viscose, mostly sustained its business by offering the product as luxury packaging. ${ }^{21}$ The 'luxury' embedded in this early history of cellophane connoted

${ }^{20}$ Judith Brown, Glamour in Six Dimensions: Modernism and the Radiance of Form (Ithaca: Cornell University Press, 2009), 145.

${ }^{21}$ Kit L. Yam, ed., The Wiley Encyclopedia of Packaging Technology (Hoboken, N.J.: John Wiley \& Sons, 2009), 527. 
not only its practicality - a convenient means of wrapping, guaranteeing freshness of the product it contained but also its visual properties, as it offered an entry point for the increasingly consumerist eye into the shape, form, and sheer materiality of what it desired, functioning as an ever-so-slightly thin line of separation. Cellophane achieved its success in the 1930s, when the company expanded its operations in the US by providing a wrapper for cigarette brands such as Camel and Lucky Strike, and the popular Whitman's chocolates. Cellophane subsequently became a ubiquitous household item, in such products as Scotch tape, but was pushed out of the packaging market by readily available alternatives like plastic wrap. The material is completely biodegradable and is therefore a subject of renewed interest, inviting speculation about how its 'luxury', associated with the nascent consumerism on the 1900 s, could be reinterpreted in environmental terms.

More to the point, Brown also indicates the resemblance between cellophane and photography: 'cellophane arrests the gaze at its glittering surface, becomes a version of the photograph, emptied of content and form [...], a blank surface that is endlessly appealing, seductive, though it transmits little beyond the wonder of its alchemy. ${ }^{22}$ It is the blankness of this transparent surface that Brown reads as a symptomatic condition of the twentieth century, as a 'nothingness' of a 'formless void', or the terrifying absence of meaning that the consumerist culture ultimately stands for. That this blankness registers in

22 Brown, Glamour in Six Dimensions, 151. 
Koyama's series in negative is one thing. The other is that Brown's binding of photography and cellophane, through their symbolical value to stand in for nothingness, also becomes pertinent to consider vis-à-vis what is broadly associated with the representation of nothingness, or the rendering of abstraction in fine art practice. ${ }^{23}$

Lyle Rexer, in his study of abstraction in photography, highlights the fact that the medium has always had a different relationship to abstraction from painting. ${ }^{24}$ Photography's mechanism for recording light forever 'wedded' it to the world, and what is most frequently termed as its indexical' nature places it in a specific position: photography is a tension between what is seen and what is understood about that which is seen in an image. ${ }^{25}$ No matter how empty an image might seem, or how nothing-like it might appear, through its nuptial relationship to the world, a photograph is always about looking. Rather than mechanisms for looking at or looking through, abstract photographs offer a means for looking with. ${ }^{26}$ Going back to Koyama's series, although we are presented with a seemingly unintelligible abstraction, conventionally understood as a representation of nothing, and conveniently rendered visible through a material that brings forth similar associations, where does it take us as a tool for looking with?

${ }^{23}$ Kirk Varnedoe, Pictures of Nothing: Abstract Art Since Pollock (Princeton, NJ: Princeton University Press, 2006).

${ }^{24}$ Lyle Rexer, The Edge of Vision: The Rise of Abstraction in Photography (New York: Aperture, 2009), 15.

25 Ibid., 15-16.

26 Ibid., 11. 


\subsection{Outside // Patterns}

To follow this line of argument a little further, let us consider another photographic series, James Welling's seminal Aluminium Foil (1980-1981). The visual similarities with Koyama's Light Field are stark, almost to the point of regarding the latter as a direct citation of the former. However, they are essentially very different projects, as Welling is using the simplest of photographic methods - close-up zooming and cropping - to maximise the abstract potential of the photographic surface. The series was produced in the artist's studio over several months after Welling became preoccupied with aluminium foil by noticing how it behaves as a packaging for butter, and was presented in 1981 at his first solo exhibition. As many writers have noted, in the close-up rendering of aluminium foil's creases, these photographs invite an associative viewing experience, something that Steyerl recently wrote about in terms of 'apophenia', or the perception of patterns within random data. ${ }^{27}$

Photography's ability to exactly re-produce patterns, or as Geoffrey Batchen frames it, to visualise mathematical information, was evidenced early on in its history. ${ }^{28}$

${ }^{27}$ For instance, James Crump notes: 'The Aluminium Foil pictures play with the surface of a known material that, when stressed and crumpled and then photographed, is capable of conjuring an image poles apart from the referent object. With surfaces on which he has amassed mesmerising quantities of detail, these photographs hold the possibility of endless readings, and [...] they rely on the beholder to fill in meaning', as per: James Crump, ed., James Welling, Monograph (New York: Aperture, 2013), 65; Steyerl, 'A Sea of Data'.

28 Geoffrey Batchen, 'Electricity Made Visible', in New Media, Old Media: A History and Theory Reader, eds. Wendy Hui Kyong Chun and Thomas Keenan (New York: Routledge, 2006), 31. 
For Batchen, it is Henry Fox Talbot's experiments with camera-less photography, and the resulting imaging of pieces of lace produced in the 1840s, that offer the point of departure for examining the tension between the photographic surface and the material that it presumably only renders visible. In the process of 'photogenic drawing' that Talbot uses, the images of lace become integrated in (rather than just on) the paper that contains them: 'figure and ground, image and support, fibres and tone, touchable reality and optical simulation, are here all collapsed in the same visual experience.2. Elsewhere, Batchen explains a range of similar photographic experiments (both historical and contemporary) through two defining characteristics: their embodiment of the duration of the action that they record and their signification of their own coming into being. ${ }^{30}$ This definition goes against the widelyadopted understanding of photography as a 'slice of time' that refers to something outside of itself and the result, often an abstract pattern, becomes 'a picture of nothing, that is, but its own capacity to represent anything. ${ }^{31}$

Batchen's writing helps us to test out the situation that Steyerl describes in photographic terms, as Welling's series deliberately invites and thereby reflects on the experience of 'apophenia'. Such inviting of what is more commonly referred to as 'free associations', is one of the defining characteristics of abstraction and has been integral to this pictorial tradition throughout the twentieth

\footnotetext{
29 Ibid., 30.

${ }^{30}$ Geoffrey Batchen, “Photography": An Art of the Real', in What is a Photograph?, ed. Carol Squiers (Munich: Prestel, 2013), 48.

31 Ibid., 54.
} 
century. ${ }^{32}$ Furthermore, in its registering of mathematical data, photography was not only always digital but was also always able to represent anything. ${ }^{33}$ Batchen highlights this intrinsic potential of photography by using inverted commas, terming it 'photography', to stress its cultural and material basis. In his view, Rexer's definition of abstract photography becomes a philosophical question: by asking us to think about how we are seeing, such photography, he claims, 'asks us to see what is right in front of our eyes. ${ }^{34}$

\subsection{Foil // Entanglement}

What do we see right in front of our eyes if we continue to 'follow' the material of abstract photography in Welling's series? Talbot's choice of the material was not divorced from the historical conditions of the machine-made lace industry in England at that time. ${ }^{35}$ In Welling's case, this makes us wonder whether it is only through its abstract rendering of the aluminium foil's surface that the artist is conveying his postmodernist criticism. ${ }^{36}$ As Mimi Sheller showed in her extensive study of aluminium, the material is possibly the richest one to 'follow' for a correct

${ }^{32}$ Varnedoe, Pictures of Nothing, 3.

33 Cubitt, Palmer and Tkacz, Digital Light, 11.

34 Batchen, “'Photography”: An Art of the Real', 60.

35 Batchen, 'Electricity Made Visible', 31.

36 Welling's practice is customarily read as an essential part of the socalled 'pictures generation' of postmodernist photographers in the US. For a well-known reference to the Aluminium Foil as 'pictures of nothing' in such a context see Abigail Solomon-Godeau, 'Playing in the Fields of the Image', Afterimage, 10, 1-2 (1982): 10-13. 
understanding of modernist logic. Although iron or plastics had their prominent roles to play in the material culture of the last century, it is aluminium that enabled the lightness and speed of the car, the train, the space shuttle, or the bomb, with which we now associate that century. On the other hand, aluminium also brings to the fore a specific twenty-first century conundrum: although its extraction continues to divide the 'developed' from the 'underdeveloped' countries and continues to play an essential part in warfare, it is increasingly becoming an essential part in the design of the new sustainable technologies. ${ }^{37}$

By the beginning of the 1980s, this conundrum had already made itself apparent. We can think of the famous décor of Andy Warhol's first 'Factory' (1962-1968), plastered in aluminium foil and silver paint to construct a dazzling, light-reflecting surface, as conveying the tension entangled with aluminium in the 1960s. Warhol saw the décor of his studio both as a futuristic setting - evoking astronaut suits or such comic book characters as 'Silver Surfer' - as well as an homage to the 'silver screen' of Hollywood. ${ }^{38}$ This tension translates into Welling's series, as it invites the viewers to project their free associations not only into an abstract pattern but into the particular material through which it takes shape; one that has already become emblematic of futurity and progress. What interests Welling is to engage visually with those materials that are in one way or another allegorical of photography (in

${ }^{37}$ Mimi Sheller, Aluminium Dreams: The Making of Light Modernity (Cambridge, Massachusetts: The MIT Press, 2014), 4.

38 Arthur Danto, Andy Warhol (New Haven: Yale University Press, 2009), 93. 
the same way that cellophane might be), and this interest is explored in his subsequent work. In this sense aluminium foil not only features a similar versatility and reflectivity to photography, but also, intentionally or not, invites the same type of progressive, futuristic and technocratic free associations as the medium that renders it visible. What we 'see in front of our eyes' in Welling's case is the entanglement of the photographic image with the technology and material that produce it, but also with the norms and effects that the same technology and material impose on our daily lives.

\subsection{Inside // Camera}

This detour allows us to realise that Koyama's series brings into the present much of photography's historical and cultural baggage, and this makes us question what else we might find entangled with it if we continued to 'follow' the material. With this question in mind, let us now come back to Yesil's Leaping Field, in which we encounter the digital camera's recording of fluorescent light as it bounces around the surface of a piece of wavy PVC (Figure 2). Although the image does not appear in the viewfinder in the process of Yesil's photographing, it reveals itself when stored in the camera's memory. As an abstraction, it invites similar projections or associative readings as to the cases of Koyama's and Welling's photographs. Similar to Koyama's series, the images are produced autonomously by the apparatus - in this instance the camera - as it is assigned the role of capturing the image through its registering of a contingent, abstract 


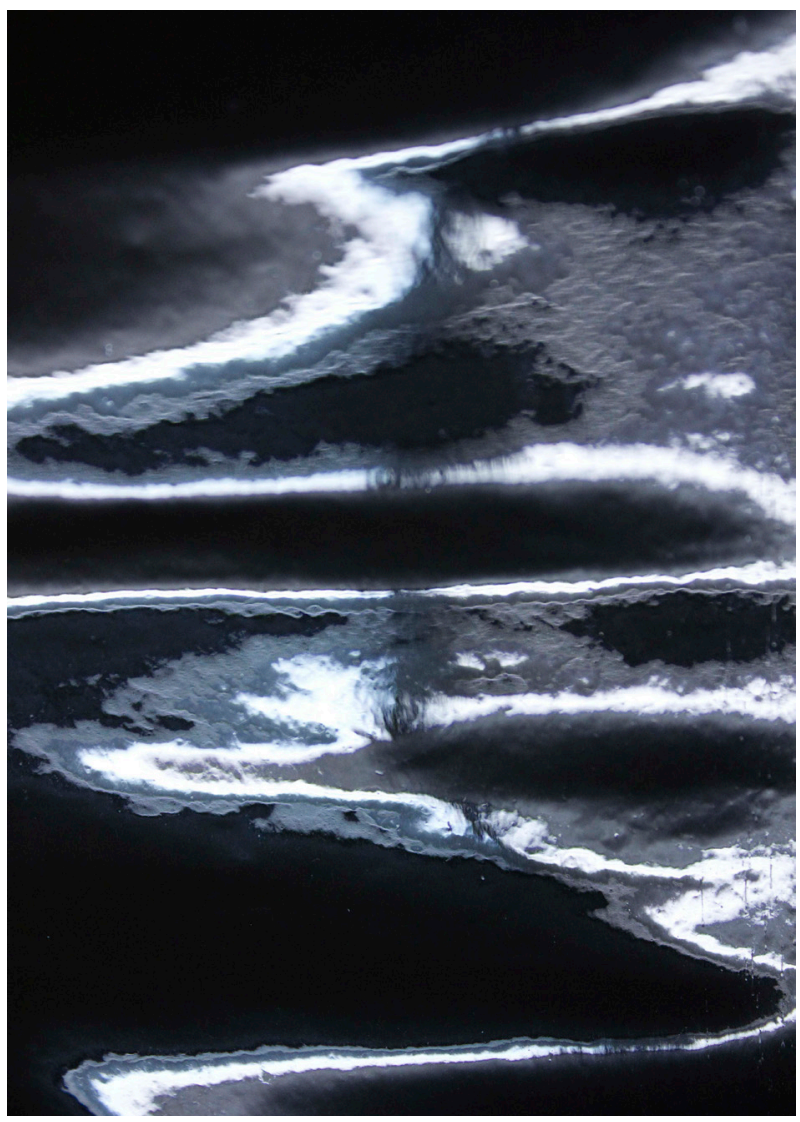

Figure 2: Nihal Yesil, Leaping Field, 2015.

pattern. Yesil, again similar to Koyama, does not seem to be photographing in a traditional sense but more to be operating the camera-machine, pointing it in the direction of the light source but letting it assume responsibility for the capture of the abstract pattern. 
The figure of the operator has been in use in the photographic jargon for some time now. It is a preferable term for Roland Barthes in his Camera Lucida: Reflections on Photography (1981), and features heavily in Vilém Flusser's Towards a Philosophy of Photography (1983). In his theory of gestures, the operator is described by Flusser as somebody who takes up an active part in the optical process of photographing, a gesture that Flusser considers to be of looking; this figure searches for and takes up a specific position, cuts through and manipulates the scene, and reflects on every decision as it is made. ${ }^{39}$ This operator, on the other hand, can also be related to the gesture of making, as this gesture involves the hand rather than the eye. ${ }^{40}$ The gesture of making involves the hand's 'grasping', 'evaluating' and 'informing' of an object, but it is also based significantly on the raw material's 'resistance' to the hand that is attempting to impress it with value. ${ }^{41}$ The photographic apparatus, or the camera, is a 'tool' that enables the gesture of photographing, which is also a gesture of making. The tool (the eye) and the body (the hand), for Flusser, are so enmeshed that assigning one or the other a specific function is pointless: defining photography as an improvement or outer-bodily extension of human sight can only be understood as a figure of speech. ${ }^{42}$

The 'raw material' evoked, in both series in question, is undoubtedly that of light, an essential component

\footnotetext{
39 Vilém Flusser, Gestures (Minneapolis: University of Minnesota Press, 2014), 72-85.

40 Ibid., 32-47.

41 Ibid., 40.

42 Ibid., 80.
} 
of both photography and vision. It is light that enables and constitutes them, entangling the operator and the recording apparatus in the process of its own entanglement with another material. In both cases, however, the artists seem to be operating the apparatuses through which light is already captured and controlled: the digital emission of LED light but also the camera itself, which is another apparatus that isolates and disciplines light. ${ }^{43}$ In such terms, Yesil's artistic intervention not only consists of letting go of the control over the framing of the image but also of her ascribing to the 'field' indicated in the title of the series the kinetic ability of 'leaping. We can consider this ability of a 'field' for movement and action to be related to the feature of surfaces that Tim Ingold describes as 'leaking..44 Ingold's argument departs from the old Aristotelian dichotomy between form and matter in which an agent imposes a form on a passive matter with a particular end or goal in mind. The similarity with photography is here straightforward, with the role of the agent played by the classical figure of the photographer, whereas the photograph can be considered to be a form imposed on the material, or matter that it renders visible. For Ingold, however, who also 'follows' the material in the sense suggested by Deleuze and Guattari posited above, the interest of an artist is not in this imposition but in

${ }^{43}$ Tim Ingold, 'Bringing Things to Life: Creative Entanglements in a World of Materials', NCRM Working Paper Series. ESRC National Centre for Research Methods, (July 2010) http://eprints. ncrm.ac.uk/1306/1/0510_creative_entanglements.pdf (accessed 22 January, 2017)

${ }^{44}$ John Tagg, The Disciplinary Frame: Photographic Truths and the Capture of Meaning (Minneapolis: University of Minnesota Press), 1. 
what he describes as: 'bringing together diverse materials and combining or redirecting their flow in the anticipation of what might emerge. ${ }^{45}$

We can also read the ability for 'leaping' of (a field of) light in Yesil's series as evoking a 'quantum leap', or a process of change induced by an abrupt movement. In both cases, it primarily indicates an interest in the merging of the materials (light-photography), within the understanding of the photographic medium as a gesture of not simply photographing but also making. However, for us to fully establish how this situation occurs in photography specifically, or how the materials not only entangle in the image but also in the apparatus that produces it, we also need to 'follow' the material that Yesil is photographing. ${ }^{46}$

\subsection{PVC// Display}

Poluvinyl chloride, better known as PVC, or just vinyl, is the second largest volume-produced plastic, characterised by toughness, low cost and the ability to modify its physical properties. ${ }^{47}$ We would normally encounter it in housing materials or telecommunication wire coatings or in such ubiquitous products as credit cards or plastic

45 Ibid., 9.

46 Yesil's particular interest in PVC began in 2007, when she bought fourteen rolls of PVC in different colours from a shop in Istanbul located on a street only selling plastic. It was also used in her previous series of images, Narrow Fields (2007), in which two layers of PVC sheets were photographed on top of each other under direct sun light. I am grateful to Nihal for explaining her interest in PVC and the details of her work to me in our e-mail correspondence in April 2016. Leaping Field is published together with Murmuring Field by Even Press in 2016.

47 Yam, The Wiley Encyclopedia, 963. 
bottles. The development of PVC, first produced in Germany in the 1930s, is, however, inseparable from the wider history of plastic, the material that came to dominate our everyday life to such an extent that we are considered to be living in the 'Plastic Age'. Plastic has been studied extensively, and the seminal texts include Roland Barthes's writing (1957) as well as Jeffrey Meikle's book about the material's integration with American culture. ${ }^{48}$ The most recent research describes the centrality of plastic to the processes of contemporary socio-material living as not only a synonym for environmental degradation but also a catalyst of causal and political reverberations that give shape to the ways we think and act. ${ }^{49}$

In addition, we cannot but notice the role that photographic technology played in the history of plastic's gradual takeover of everyday life, and vice versa. It was the popularity of photographic film, after all, that helped market the early uses of celluloid, regardless of its thermal instability. ${ }^{50}$ On the other hand, although analogue photography is conventionally associated with photographic chemicals and photosensitive paper, it is celluloid film and the Bakelite cameras that popularised the technology. ${ }^{51}$ The history of photography, undoubtedly, is also a history of plastic. Therefore, that plastic plays a decisive

48 Roland Barthes, Mythologies, (London: Vintage, 2009), 117-119; Jeffrey Meikle, American Plastic: A Cultural History, (New Brunswick, NJ Rutgers University Press, 1995).

49 Jennifer Gabrys, Gat Hawkins, and Mike Michael, eds., Accumulation: The Material Politics of Plastic (Abingdon, Oxon: Routledge, 2013), 2-4.

50 Ibid., 19.

${ }^{51}$ Stephen Fenichell, Plastic: The Making of a Synthetic Century (New York: Harper Business, 1996). 
role for not only how images are captured but also for how they are most often displayed and viewed in modern culture - through digital interfaces infused with plastic and often navigated by touching as much as by looking is another nodal point of entanglement that the PVC used in Yesil's series makes us account for.

\subsection{Summary // Field}

According to Peter Galassi, the ultimate origin of photography needs to be looked for in the invention of linear perspective in the fifteenth century. ${ }^{52}$ Unlike those accounts that establish photography's emergence in the technological development of the camera obscura since the Renaissance, this one insists that photography's coming to being was not divorced from a more general history of seeing. As is well known, this invention brought about the ordering of what was visible in the perceptual field in relation to not only modern science but also emerging capitalism. ${ }^{53}$ If we take it that such an ordering - of the field of vision, its digital constitution in light, or its material basis continues to determine digital vision, we might presume that abstract photography, the 'pictures of nothing' that we encountered here through the work of Koyama and Yesil, suggest an antagonistic or an oppositional intention. In order to accurately understand where precisely these artistic interventions take place, however, we now need to

52 Peter Galassi, Before Photography: Painting and the Invention of Photography (New York: Museum of Modern Art, 1981), 12.

53 Jay, Downcast Eyes, 57. 
turn to what is understood by 'nothingness' in quantum physics, as explained to us by Karen Barad.

For Barad, to even start thinking or speaking about nothingness implies asking what is the measure of nothingness according to which we might grasp it. ${ }^{54}$ Measurements, however, require specific measurement apparatus and their working cannot be understood in terms of an interaction with what is being measured but rather as intra-action, in that observation is inseparable from what is observed. ${ }^{55}$ Importantly for us, it is light that Barad takes as an example of this claim: as the 'wave-particle duality paradox' evidences, when the electrons of light are measured using one kind of apparatus they are waves, but when they are measured with another (complementary apparatus) they are particles. ${ }^{56}$ In such a manner, it is indeterminacy that lies at the core of quantum physics' understanding of nothingness, but this indeterminacy signals not an absence, but a radical kind of openness, characterised by an infinity of possibilities. ${ }^{57}$

What does this mean to us? We can regard indeterminacy vis-à-vis photography's self-entanglement that Frampton helped us to identify - the inability to divorce 'fine art' from 'evidence' - which is still at the core of the medium's misinterpretation, even in the digital 'turn.'58 Following Batchen, however, we can safely conclude that

${ }^{54}$ Karen Barad, What is the Measure of Nothingness? Infinity, Virtuality, Justice (Osfildern: Hatje Cantz, 2012), 5.

55 Ibid., 6.

56 Ibid.

57 Ibid., 16.

${ }_{58}$ Martin Lister, ed., The Photographic Image in Digital Culture (London: Routledge, 1995), 16. 
even when operating at the 'edge of vision' - as fine art and abstraction - photography never escapes the ordering and re-ordering of the field of vision, of which it is always a part, and which is always already controlled by the apparatus that tame and discipline light. Indeterminacy, however, has larger implications for us here in terms of the entanglements that we identified to be central to photography's practice: between the operator and the machine, as well as between the technology and the material. 'Following' the material, or beginning to do so (in the cases of cellophane, aluminium foil and PVC but also light), we established that especially the latter entanglement operates on multiple levels in photographic terms. Photography does not simply represent materials but is equally made of them. Furthermore, the materials that photography represent and of which it consists are not only intrinsically unstable and in constant flux, but are sometimes allegorical of each other or literally one and the same. Finally, photography also makes with the material, that of light, and this fact potentially places the medium in an important relation to what Barad terms to be radical openness at the core of all matter.

\subsection{Proposition // Waves}

Barad's project of agential realism is based on a strong commitment to, what she defines as, 'accounting for the material nature of practices and how they come to 
matter. ${ }^{59}$ The first step for the development of this project is a strong critique of representationalism, or a distinction that is customarily made between representations and that which they aspire to represent in Western philosophical thought. ${ }^{60}$ Here we find a very potent framework for better understanding the position of our two series, as Barad takes up the working of the scanning tunnelling microscopes (STM) to demonstrate her criticism. Although normally associated with the processes of seeing, these machines are essentially based more on the sense of touch than sight and are described as forming images of atoms 'in a way which is similar to the way a blind person can form a mental image of an object by feeling the object. ${ }^{61}$ Moreover, the STM operator does more than simply 'push a button' for an image to appear; the 'seeing' of an atom is not simply a process of magnification but involves a series of practices, including complex and detailed preparations of both the microscope and the specimen. This leads Barad to conclude that, 'images and representations are not snapshots or depictions of what awaits us but rather condensations or traces of multiple practices of engagement. ${ }^{62}$

For photography, a quintessential instance of the practices of representation, this statement holds significant repercussions that lie beyond the two series of our interest,

\footnotetext{
${ }^{59}$ Karen Barad, Meeting the Universe Halfway: Quantum Physics and the Entanglement of Matter and Meaning (Durham: Duke University Press, 2007), 45.

60 Ibid., 46.

61 Ibid., 52.

62 Ibid., 53.
} 
but which they can be seen to be exemplary of. In terms of those series in particular, they seem to be positioned in the channels of 'tunnelling' through which STM functions, as the process allows particles to traverse energy barriers that Newtonian physics imposes on them..$^{63}$ STM, in other words, not only requires the apparatus to 'touch-see' the object but also the object to come and 'meet it', and this point of intra-action, in Barad's terms, is where both Koyama and Yesil base their artistic interventions: as primarily photographic experiments, they do not take place outside but inside the phenomena that they represent. By doing so, and by functioning as tools for looking with, they push open the door into a possible rethinking of their medium and, implicitly, into the very understanding of digital vision.

Here, it is time for us to come up with a preliminary proposition. As Orit Halpern also suggests, digital vision, in its entanglement with data visualisations that increasingly require haptic forms of interactivity, cannot be taken to be an isolated form of perception but needs to be understood as inseparable from other senses. ${ }^{64}$ Barad herself has already demonstrated the limitation of the concept of machinic vision, recognised also by Johnston at the moment of its definition, which becomes ostensible when placed in constellation with such non-human agents as animals. ${ }^{65}$ If by this we succeeded in attending,

63 Ibid., 52.

${ }^{64}$ Orit Halpern, Beautiful Data: A History of Vision and Reason Since 1945 (Durham: Duke University Press, 2014), 21.

65 Karen Barad, 'Invertebrate Visions: Diffractions of the Brittlestar', in The Multispieces Salon, ed. Eben Kirksey (Durham: Duke University Press, 2014). For Johnston, the limitations of machinic vision become apparent in terms of the inevitability of artificial, or vir- 
at least to some extent, to the problem of representation, we are still left with the one of regulation that we started from, and our proposition then requires one final stretch. In order to deliver her critique of representationalism, Barad turns to the principle of diffraction, a phenomenon that is of central importance to her project. She explains diffraction in terms of physics as a particular behaviour of waves, which combine and overlap once they encounter an obstruction. ${ }^{66}$ This behaviour is central to all kinds of waves, whether water, sound or light, and differentiates them from particles: unlike particles (material entities occupying a point in space and time) waves are not things per se but rather 'disturbances that propagate in a medium' (and that can overlap at the same point in space).${ }^{67}$ Diffraction plays a role in nearly all optical phenomena, and we can observe it in our two series not only through what we come to see but also through how we come to see it, as diffraction poses a limit to the resolving power of a lens or any other visualising system. ${ }^{68}$

Diffraction is not only an optical phenomenon that Barad helps us to understand but also a methodological approach that she adopts from Donna Haraway. Following Haraway, Barad proposes diffraction as an alternative to the optical metaphor of reflection, in that: whereas reflection is about mirroring and sameness, diffraction

tual reality that the digital image foreshadows. For the resonance of Barad's writing in this field see: Jane Prophet and Helen Pritchard, 'Performative Apparatus and Diffractive Practices: An Account of Artificial Life Art', Artificial Life 21, no. 3 (2015): 332-343.

${ }_{66}$ Barad, Meeting the Universe Halfway, 74.

67 Ibid., 75.

68 Barad, 'Invertebrate Visions', 231. 
attends to patterns of difference. ${ }^{69}$ This suggestion is of huge resonance and offers us with a starting point to redefine nothing less than the very basis of science and ethics. And it appears to indicate that by 'following' the material we find ourselves questioning the essential parameters of both vision and ethics. Rather than risking over-simplification and analogy at this point, it seems more appropriate that we leave it at that, in an open ending that also reads as a beginning.

\section{References}

Barad, Karen. Meeting the Universe Halfway: Quantum Physics and the Entanglement of Matter and Meaning. Durham: Duke University Press, 2007.

Barad, Karen. What is the Measure of Nothingness? Infinity,

Virtuality, Justice. Osfildern: Hatje Cantz, 2012.

Barad, Karen. 'Invertebrate Visions: Diffractions of the Brittle-

star'. In The Multispecies Salon, edited by Eben Kirksey. Durham: Duke University Press, 2014.

Barthes, Roland. Mythologies. London: Vintage, 2009.

Barthes, Roland. Camera Lucida: Reflections on Photography.

New York: Hill and Wang, 1981.

Batchen, Geoffrey, 'Electricity Made Visible.' In New Media, Old

Media: A History and Theory Reader, edited by Wendy Hui,

Kyong Chun and Thomas Keenan. New York: Routledge, 2006. Batchen, Geoffrey. "Photography": An Art of the Real'. In What is a Photograph?, edited by Carol Squiers. Munich: Prestel, 2013. Brown, Judith. Glamour in Six Dimensions: Modernism and the Radiance of Form. Ithaca: Cornell University Press, 2009.

Crump, James, ed. James Welling, Monograph. New York: Aperture, 2013.

69 Barad, Meeting the Universe Halfway, 29. 
Cubitt, Sean. The Practice of Light: A Genealogy of Visual Technologies from Prints to Pixels. Cambridge, Massachusetts: The MIT Press, 2014.

Cubitt, Sean, Daniel Palmer, and Nathaniel Tkacz, eds. Digital Light. London: Open Humanities Press, 2015.

Danto, Arthur. Andy Warhol. New Haven: Yale University Press, 2009.

Deleuze, Gilles. 'Postscript on the Societies of Control', October 59 (1992): 3-7.

Deleuze, Gilles and Félix Guattari. A Thousand Plateaus: Capitalism and Schizophrenia. Minneapolis: University of Minnesota Press, 1987.

Fenichell, Stephen. Plastic: The Making of a Synthetic Century. New York: Harper Business, 1996.

Flusser, Vilém. Towards a Philosophy of Photography. London: Reaktion, 2000.

Flusser, Vilém. Gestures. Minneapolis: University of Minnesota Press, 2014.

Frampton, Hollis and Bruce Jenkins. On the Camera Arts and Consecutive Matters: The Writings of Hollis Frampton. Cambridge, Massachusetts: The MIT Press, 2009.

Gabrys, Jennifer, Gat Hawkins, and Mike Michael, eds. Accumulation: The Material Politics of Plastic. Abingdon, Oxon: Routledge, 2013.

Galassi, Peter. Before Photography: Painting and the Invention of Photography. New York: Museum of Modern Art, 1981.

Helpern, Orit. Beautiful Data: A History of Vision and Reason Since 1945. Durham: Duke University Press, 2014.

Ingold, Tim. 'Bringing Things to Life: Creative Entanglements in a World of Materials'. NCRM Working Paper Series. ESRC National Centre for Research Methods, (July 2010). Accessed 22 January, 2017 http://eprints.ncrm.ac.uk/1306/1/0510_ creative_entanglements.pdf

Jay, Martin. Downcast Eyes: The Denigration of Vision in Twentieth-Century French Thought. Berkeley: University of California Press, 1993.

Johnston, John. 'Machinic Vision'. Critical Inquiry 26 (1999): 27-48. 
Jones, Stephen. 'What is Digital Light?'. In Digital Light, edited by Sean Cubitt, Daniel Palmer, and Nathaniel Tkacz. London: Open Humanities Press, 2015.

Lange-Berndt, Petra, ed. Materiality. London: Whitechapel Gallery; Cambridge, Massachusetts: The MIT Press, 2015.

Leising, Günter. 'Light and Order'. In Light Art from Artificial Light: Light as a Medium in $20^{\text {th }}$ and $21^{\text {st }}$ Century Art, edited by Peter Weibel. Ostfildern: Hatje Cantz, 2006.

Lister, Martin, ed. The Photographic Image in Digital Culture. London: Routledge, 1995.

Meikle, Jeffrey. American Plastic: A Cultural History. New Brunswick, NJ: Rutgers University Press, 1995.

Moschovi, Alexandra, Carol McKay, Arabella Plouviez, eds. The Versatile Image: Photography, Digital Technologies and the Internet. Leuven: Leuven University Press, 2013.

Parikka, Jussi. A Geology of Media. Minneapolis: University of Minnesota Press, 2015.

Prophet, Jane and Helen Pritchard. 'Performative Apparatus and Diffractive Practices: An Account of Artificial Life Art'. Artificial Life 21, no. 3 (2015): 332-343.

Rexer, Lyle. The Edge of Vision: The Rise of Abstraction in Photography. New York: Aperture, 2009.

Rubenstein, Daniel, and Jonny Golding, and Andy Fisher, eds. On the Verge of Photography: Imaging Beyond Representation. Birmingham: Article, 2013.

Sheller, Mimi. Aluminium Dreams: The Making of Light Modernity. Cambridge, Massachusetts: The MIT Press, 2014.

Solomon-Godeau, Abigail. 'Playing in the Fields of the Image'. Afterimage 10, no. 1-2 (1982): 10-13.

Steyerl, Hito. 'A Sea of Data: Apophenia and Pattern (Mis-)Recognition', E-flux Journal 72 (2016). Accessed 22 January, 2017 http://www.e-flux.com/journal/a-sea-of-data-apopheniaand-pattern-mis-recognition

Tagg, John. The Burden of Representation: Essays on Photographies and Histories. Amherst: University of Massachusetts Press, 1988. 
Tagg, John. The Disciplinary Frame: Photographic Truths and the Capture of Meaning. Minneapolis: University of Minnesota Press, 2009.

Varnedoe, Kirk. Pictures of Nothing: Abstract Art Since Pollock. Princeton, NJ: Princeton University Press, 2006.

Yam, Kit L., ed. The Wiley Encyclopedia of Packaging Technology. Hoboken, N.J.: John Wiley \& Sons, 2009.

\section{Hyperlinks}

Aluminium Foil: http://www.davidzwirner.com/artists/jameswelling/survey/image/page/56/

pieces of lace: https://www.artsy.net/artwork/william-henryfox-talbot-lace 
